\title{
Manufacturing of complex geometric structure metal matrix structures used for special purposes
}

\author{
Bekir Ekinli' ${ }^{1}$, Mehmet Kaba ${ }^{2}$, Sezgin Ersoy ${ }^{3}$ \\ ${ }^{1,3}$ Enformak Design Center, İstanbul, Turkey \\ ${ }^{2,3}$ Mechatronic Engineering Technology Faculty Marmara University, Istanbul, Turkey \\ ${ }^{3}$ Corresponding author \\ E-mail: ${ }^{1}$ bekire@enformak.com, ${ }^{2}$ mhmtkb71@gmail.com, ${ }^{3}$ sersoy@marmara.edu.tr
}

Received 8 November 2021; received in revised form 3 December 2021; accepted 11 December 2021 DOI https://doi.org/10.21595/jmai.2021.22335

Copyright $(2021$ Bekir Ekinli, et al. This is an open access article distributed under the Creative Commons Attribution License, which permits unrestricted use, distribution, and reproduction in any medium, provided the original work is properly cited.

\begin{abstract}
Three-dimensional (3D) production systems are making rapid progress and their needs are met in every field from the construction sector to the food sector. This technology is based on a hardware called the 3D printer which performs layered production. These printers are used in producing both prototypes and machine parts and mold tools. 3D prints can be produced using 3D printers with that are based on different technologies. These production systems have some disadvantages as well as the advantages they provide. Filament supported productions have a common problem if the fluid gets stuck in the flow line. In this study, screw extruder design and product development will be provided as a new generation production technology to be used in additive production as an innovative approach in additive manufacturing technology.
\end{abstract}

Keywords: 3D printer, Additive manufacturing, extruder screw.

\section{Introduction}

$3 \mathrm{D}$ printing is an additive manufacturing technique which is used to produce various structures and complex geometries from model data. Production is carried out by printing successive layers of material on top of each other. This technology was named stereolithography (SLA) by Charles in 1986, and later generations such as melt agglomeration modeling (FDM) and inkjet printing emerged [1]. Incorporating a variety of methods, materials and equipment, 3D printing has evolved over the years and has the ability to transform manufacturing and logistics processes. Additive manufacturing is widely applied in different industries such as defense industry [2], aerospace [3], construction [4], prototyping and biomechanics [5]. This method provides less design, less material waste and enhanced automation freedom.

Developing technology reveals new applications and new materials in additive manufacturing. In addition, new additive manufacturing methods are constantly being developed. One of the main reasons this technology has become more accessible is because previous patents that allowed manufacturers to develop new 3D printing devices have expired and technologies have become available. Recent developments reduce the cost of 3D printers. Thus, the field of application spreads to large areas such as schools, homes, libraries, and laboratories. 3D printing can also be used by architects and designers to produce aesthetic and functional prototypes due to its rapid and cost-effective prototyping capabilities. The use of 3D printing minimizes the additional costs incurred in a product development process. For example, costs may increase as a result of demands for special products or large quantities of products. Special products, which are defined as a substance that is the result of biological, chemical, or physical changes from one or more other materials, can be 3D printed in small quantities at relatively low cost by additive manufacturing. Customized functional products currently make up about $50 \%$ of the 3D printing industry [6]. This technology contributes to the production of a wide variety of medical supplies and implants, as well as the aerospace industry [7-10].

Designers must have the ability to objectify and generate their ideas. However, in the process of objectifying ideas, stages such as sandblasting, cutting and prototype processes take a lot of time. Transforming a computer-aided 3D design into a solid object is an important step in the 
design process [11]. In this method (12), where printing is made in the form of layers, the productivity of the produced material is increased, and the production time is shortened. This production technique also provides design freedom and facilitates the production of parts with complex geometries [13]. 3D printers are new-age production tools that work with inkjet or laser. Transform products from digital media into 3D solid objects in a layer-based structure defined as additive production [14]. It can be produced with three-dimensional printers with different technologies. Production technologies with 3D technology are shown in Fig. 1 [15-17].

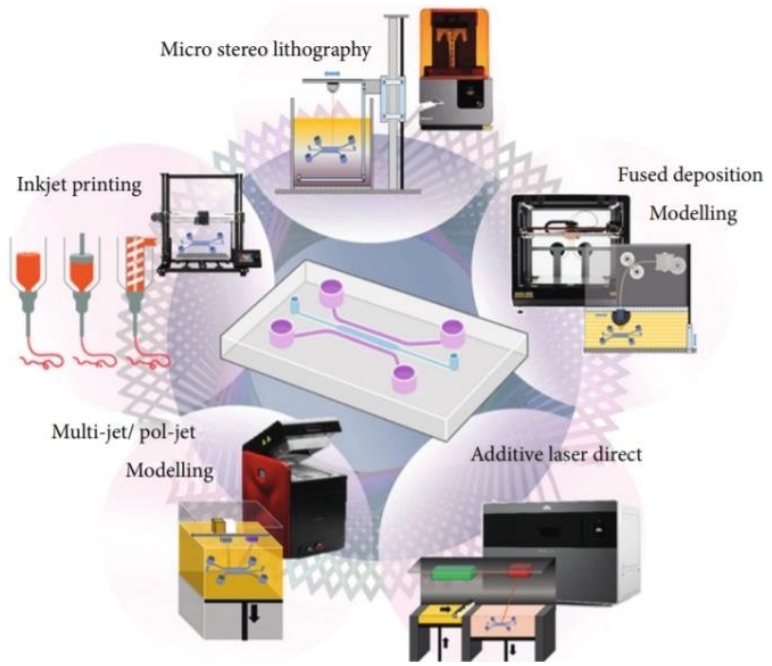

Fig. 1. 3D technology production method (15-17)

The most common of these technologies is FDM (Fused Deposition Modeling) technology. SLS (selective laser sintering) is another widely used method. The Sintering technology of the SLS method generally involves the conversion of powdered metals used in powder metallurgy into solid objects under pressure and heat (18).

The use of 3D printers has many advantages for companies engaged in production in the aviation industry. Especially the production of parts with complex geometry is challenging for the manufacturer. Looking at the last 25 years, complex pieces in the form of mechanical parts come to the fore. In addition, many problems arise when the production of these parts is made with conventional production methods. The important thing is to reduce the cost by simplifying the production and manufacturing process. Product designers can improve the properties of the part to be produced with minor corrections in this manufacturing method. The solution of functional and aesthetic problems can be solved with 3D printing technologies. In addition, parts of a multicomponent design can be printed as a whole. This is an important issue in terms of cost and time. Fewer parts allow for less assembly analysis and less complexity. This technology has started to be used in every sector and has started to take place in the automation process. This article aims to develop products for adapting screw sleeve technology to 3D printers with an innovative approach in additive manufacturing technologies.

\section{Method}

A widely used filament based additive manufacturing process [19, 20]. The roller thermoplastic polymer filaments are fed into the compactor using a compression feed mechanism $[21,22]$. In accordance with the pattern created from the 3D model, the polymer is extruded by stacking on the build platform or on the previous layer. In the next step, after the layer is processed, a new layer is stacked at a distance of one layer thickness from the building platform and the model is created. 
By using it in additive production in extrusion production, it will be produced in a very narrow diameter tolerance that cannot be obtained in the traditional method [23, 24]. Because the filamentbased 3D printer driver pushes the filament feedstock through the fluidizer, a change in diameter can cause clogging. A filament with a too large diameter will block the system, a filament with a too small diameter will not touch the extruder wall and will cause the material to rise between the wall and the filament. Other disadvantages of this process are buckling [22, 25, 26] and slippage of the filament on the compression wheel [26], which interrupts the build process and requires operator intervention [21, 23-25].

In this study, screw extruder design and product development will be provided for the next generation production technology to be used in additive production as an innovative approach in additive manufacturing technology. The technical drawing of the product will be created by examining the existing system. Modeling will be done with Finite Element Analysis and the potential of the designed product under the determined working conditions will be evaluated. After the design is completed, the screw design will be produced by CNC.

In the feeding system we designed in the study, material will be fed from outside the system. The material will be directly transferred to the screw channel and conveyed to the nozzle. meanwhile, the transported polymeric material is heated by the screw. The material comes into the empty space between the auger base and the nozzle, called the buffer zone. Meanwhile, the material trying to pass through the narrow wall will reach the nozzle. A pressure gradient is created in the agglomerated material and the nozzle resistance causes extrusion. While there is indeed a transitional phase between solid and liquid, simplifying the material phase transition as a boundary would help develop a model for the system. (Fig. 2).
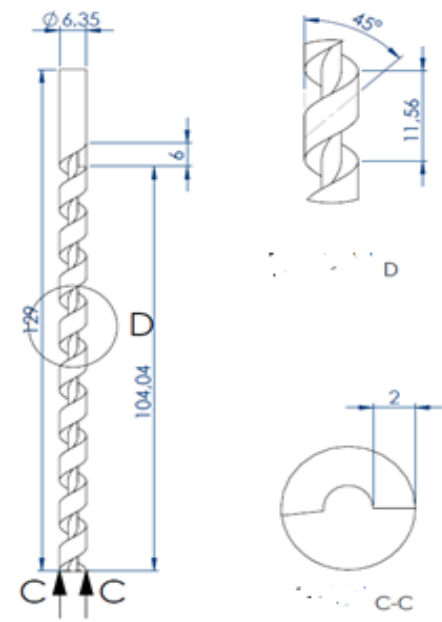

Fig. 2. Extrusion screw design for additive manufacturing

The material that can be used in traditional additive manufacturing is limited. However, in our proposed method, increased material options can be used depending on the feeding of the material. Thermoplastic material in granular form instead of filament is conveyed to the nozzle by extrusion of bulk material. The pressure created by the application of heat to soften the polymer granules into a viscoelastic melt expels the air trapped between the granules. Back pressure caused by the nozzle shape is overcome by the extrusion process [25-28]. The complex design and structure of the required three-section screw can be difficult to manufacture. However, this complex structure of the product will prevent the extrusion from being interrupted and will serve to prevent the air trapped in the polymer melt. Fig. 4 shows the design of the screw extruder unit. In addition to the screw, sleeve, and nozzle, a frame is also implemented for mounting the printhead to the CMM's refitted frame. There will also be a total of $3 \mathrm{~kW}$ to assist in melting the thermoplastic material. 
1.8550 Nitriding Steel will be used for screw production. Nitriding steels are the group that gives the best response to nitration heat treatment. Thanks to the aluminum it contains, its nitration ability (nitrogen absorption) is high. It is a pre-hardened material with a surface hardness of 66-68 HRc thanks to the aluminum nitride layer, and its delivery hardness varies between 27-33 HRc. The nitration depth can reach up to $0.10 \mathrm{~mm}$. It is very difficult to reach a thickness of $0.04 \mathrm{~mm}$ in other types of steel. Since nitration is a process that does not pose a problem in terms of dimensional stability, it is mostly preferred in parts with dimensional accuracy and in tools that will not be chipped after heat treatment. 8550 is steel with very good nitriding ability and high aluminum alloy nitration surface absorption ability. It is generally used in screw sleeve assemblies in plastic extrusion machines. With a delivery hardness of $30 \mathrm{hrc}$ and nitration, a hardness of $60 \mathrm{hrc}$ up to $0.40 \mathrm{~mm}$ can be obtained on the surface.

Metal alloy called Nitrating Steel was used in the study. Material information is shown in Table 1. Finite element analysis was applied using the material. As a result of the analysis, the results regarding the mechanical and thermal properties are presented.

\section{Conclusions}

Finite element Analysis data applied to Nitrating 8550 steel are shown in the study. Thermal, Mechanical and Abrasion analyzes were applied on the effects that the material would be exposed to during work. Thermal analyzes were applied using the material and its volumetric properties are shown in Table 1.

Table 1. Finite element analysis results of the screw produced from 8550 nitrating steel

\begin{tabular}{|c|c|}
\hline Finite element analysis & Result \\
\hline Yield strength & $680 \mathrm{~N} / \mathrm{m}^{2}$ \\
\hline Thermal & $430 \mathrm{C}$ \\
\hline Torsion & $88.92 \mathrm{~N} \cdot \mathrm{m}$ \\
\hline
\end{tabular}

In the study, examinations were made for the screw developed for the new generation production technology to be used in production. When the screw design data to be used in the system is examined, it has been determined that 1.8550 Nitriding Steel is the most suitable material in terms of machinability, availability, and cost. The technical design has been made for the material produced from nitriding steel and its position in the system. In addition, the thermal analyzes of the material were examined and it was seen that it has a structure that will not be adversely affected by the amount of heat that the system can produce.

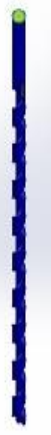

a)

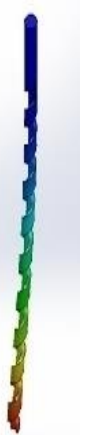

b)

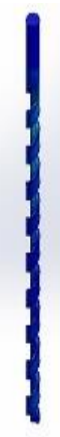

c)

Fig. 3. a) Thermal analysis, b) bending value and c) yield strength data of $3 \mathrm{~d}$ Printer extrusion screw produced from 8550 Nitriding steel

The mechanical results show that the material responds adequately under operating conditions. (Fig. 3). It is also seen in the tribological analysis of the material when it is suitable for working 
conditions. The design and manufacture of the product that can be used for the Screw Extrusion Systems to be developed for additive production, and the technical feature screw design in accordance with the production management was carried out.

\section{References}

[1] T. D. Ngo, A. Kashani, G. Imbalzano, K. T. Q. Nguyen, and D. Hui, "Additive manufacturing (3D printing): a review of materials, methods, applications and challenges," Composites Part B: Engineering, Vol. 143, pp. 172-196, Jun. 2018, https://doi.org/10.1016/j.compositesb.2018.02.012

[2] M. Kalender, S. E. Kilic, S. Ersoy, Y. Bozkurt, and S. Salman, "Additive manufacturing and 3D printer technology in aerospace industry," in 2019 9th International Conference on Recent Advances in Space Technologies (RAST), pp. 689-694, Jun. 2019, https://doi.org/10.1109/rast.2019.8767881

[3] Joshi, S. C., Sheikh, and A. A., "3D printing in aerospace and its long-term sustainability," Virtual and Physical Prototyping, Vol. 10, No. 4, pp. 175-185, 2015.

[4] Y. W. D. Tay, B. Panda, S. C. Paul, N. A. Noor Mohamed, M. J. Tan, and K. F. Leong, "3D printing trends in building and construction industry: a review," Virtual and Physical Prototyping, Vol. 12, No. 3, pp. 261-276, Jul. 2017, https://doi.org/10.1080/17452759.2017.1326724

[5] Temiz I. and Ersoy S., "Individual custom design and production of artificial organs," in 2nd International Congress on Advances in Bioscience and Biotechnology (ICABB), June 26-30, 2018 Podgorica, Montenegro, 2018.

[6] B. Berman, "3-D printing: The new industrial revolution," Business Horizons, Vol. 55, No. 2, pp. 155162, Mar. 2012, https://doi.org/10.1016/j.bushor.2011.11.003

[7] D. Khorsandi et al., "Manufacturing of microfluidic sensors utilizing 3d printing technologies: a production system," Journal of Nanomaterials, Vol. 2021, pp. 1-16, Aug. 2021, https://doi.org/10.1155/2021/5537074

[8] K. Özsoy and B. Duman, "Usability of additive manufacturing (3D Printing) technologies in education," International Journal of $3 D$ Printing Technologies and Digital Industry, Vol. 1, No. 1, pp. 36-48, 2017.

[9] A. Çelebi, H. Tosun, and A. C. Önçağ, "3D Printer manufacturing and implant design of a damaged skul," International Journal of 3D Printing Technologies and Digital Industry, Vol. 1, No. 1, pp. 27 $35,2017$.

[10] T. Abe and H. Sasahara, "Dissimilar metal deposition with a stainless steel and nickel-based alloy using wire and arc-based additive manufacturing," Precision Engineering, Vol. 45, pp. 387-395, Jul. 2016, https://doi.org/10.1016/j.precisioneng.2016.03.016

[11] J. W. Stansbury and M. J. Idacavage, "3D printing with polymers: challenges among expanding options and opportunities," Dental Materials, Vol. 32, No. 1, pp. 54-64, Jan. 2016, https://doi.org/10.1016/j.dental.2015.09.018

[12] P. Wu, J. Wang, and X. Wang, "A critical review of the use of 3-D printing in the construction industry," Automation in Construction, Vol. 68, pp. 21-31, Aug. 2016, https://doi.org/10.1016/j.autcon.2016.04.005

[13] L. Calli and K. Taskin, "A review on emerging markets and marketing activities with 3D printing industry," in 15th International Conference on Electronic Business (ICEB 2015), Jun. 2015.

[14] D. Çelik and K. Çetinkaya, "3D printer designs, prototypes and product printing comparisons," Journal of Advanced Technology Sciences, Vol. 5, No. 2, pp. 151-163.

[15] D. Khorsandi et al., "3D and 4D printing in dentistry and maxillofacial surgery: printing techniques, materials, and applications," Acta Biomaterialia, Vol. 122, pp. 26-49, Mar. 2021, https://doi.org/10.1016/j.actbio.2020.12.044

[16] A. K. Miri, E. Mostafavi, D. Khorsandi, S.-K. Hu, M. Malpica, and A. Khademhosseini, "Bioprinters for organs-on-chips," Biofabrication, Vol. 11, No. 4, p. 042002, Sep. 2019, https://doi.org/10.1088/1758-5090/ab2798

[17] S. N. Economidou and D. Douroumis, "3D printing as a transformative tool for microneedle systems: Recent advances, manufacturing considerations and market potential," Advanced Drug Delivery Reviews, Vol. 173, pp. 60-69, Jun. 2021, https://doi.org/10.1016/j.addr.2021.03.007

[18] S. W. Williams, F. Martina, A. C. Addison, J. Ding, G. Pardal, and P. Colegrove, "Wire+arc additive manufacturing," Materials Science and Technology, Vol. 32, No. 7, pp. 641-647, 2016.

[19] Terminology for Additive Manufacturing Technologies. West Conshohocken, PA: ASTM International, 2010, https://doi.org/10.1520/f2792-10 
[20] J.-P. Kruth, M. C. Leu, and T. Nakagawa, "Progress in additive manufacturing and rapid prototyping," CIRP Annals, Vol. 47, No. 2, pp. 525-540, 1998, https://doi.org/10.1016/s0007-8506(07)63240-5

[21] I. Gibson, D. W. Rosen, and B. Stucker, Additive Manufacturing Technologies. Boston, MA: Springer US, 2010, https://doi.org/10.1007/978-1-4419-1120-9

[22] B. V. Reddy, N. V. Reddy, and A. Ghosh, "Fused deposition modelling using direct extrusion," Virtual and Physical Prototyping, Vol. 2, No. 1, pp. 51-60, Mar. 2007, https://doi.org/10.1080/17452750701336486

[23] S. H. Masood and W. Q. Song, "Thermal characteristics of a new metal/polymer material for FDM rapid prototyping process," Assembly Automation, Vol. 25, No. 4, pp. 309-315, Dec. 2005, https://doi.org/10.1108/01445150510626451

[24] James Comb, William Priedeman, Paul Leavitt, Robert Skubic, John Batchelder, and Stratasys Inc, "High-precision modeling filament," Patent US6866807B2, 2005.

[25] A. Bellini, S.U. Gu"C. ,Eri, and M. Bertoldi, "Liquefier dynamics in fused deposition," Journal of Manufacturing Science and Engineering, Vol. 126, No. 2, pp. 237-246, May 2004, https://doi.org/10.1115/1.1688377

[26] N. Venkataraman et al., "Feedstock material property - Process relationships in fused deposition of ceramics (FDC)," Rapid Prototyping Journal, Vol. 6, No. 4, pp. 244-253, Dec. 2000, https://doi.org/10.1108/13552540010373344

[27] H. Valkenaers, F. Vogeler, E. Ferraris, A. Voet, and J.-P. Kruth, "A novel approach to additive manufacturing: screw extrusion 3D-printing," in 10th International Conference on Multi-Material Micro Manufacture, pp. 235-238, 2013, https://doi.org/10.3850/978-981-07-7247-5-359

[28] A. Bellini, L. Shor, and S. I. Guceri, "New developments in fused deposition modeling of ceramics," Rapid Prototyping Journal, Vol. 11, No. 4, pp. 214-220, Sep. 2005, https://doi.org/10.1108/13552540510612901

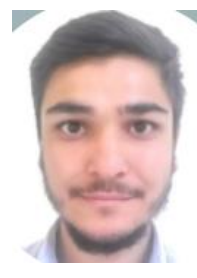

Bekir Ekinci is currently a manager and research engineer of Enformak Design Center. His current research interest design of components, unmanned arial vehicle and machine designing.

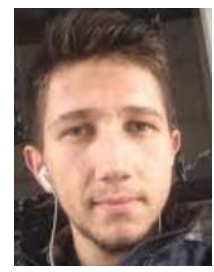

Mehmet Kaba is currently an undergraduate student in Marmara University, Mechatronics Engineering department. His current research interests include electronic, $3 \mathrm{D}$ printer and design.

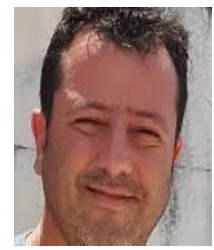

Sezgin Ersoy is an Associate Professor of mechatronics engineering and material science. After graduating from Marmara University, he became a faculty member at the same university. His publications include a variety of efforts to understand changes in automotive mechatronics, polymer science and biomedical technologies. He is the editor and author of books. He has two science national awards and is an Editorial Member of several scientific journals. 